The causal relationship between sexual selection and sexual size dimorphism in marine gastropods

Terence P. T. Ng ${ }^{1, a}$, Emilio Rolán-Alvarez ${ }^{2,3, a}$, Sara Saltin Dahlén ${ }^{4}$, Mark S. Davies ${ }^{5}$, Daniel Estévez², Richard Stafford ${ }^{6}$, Gray A. Williams ${ }^{1 *}$

1 The Swire Institute of Marine Science and School of Biological Sciences, The University of Hong Kong, Pokfulam Road, Hong Kong SAR, China 2 Departamento de Bioquímica, Genética e Inmunología, Facultad de Biología, Universidad de Vigo, 36310 Vigo Spain 3 Centro de Investigación Mariña da Universidade de Vigo

4

Department of Marine Sciences - Tjärnö, University of Gothenburg, SE-452 96 Strömstad, Sweden 5 Faculty of Applied Sciences, University of Sunderland, Sunderland, U.K. 6

Faculty of Science and Technology, Bournemouth University, U.K.

a Contributed equally to this work

*Correspondence: Gray A. Williams, The Swire Institute of Marine Science, The University of Hong Kong, Pokfulam Road, Hong Kong

E-mail: hrsbwga@hku.hk

Telephone: (852) 28092551

Fax: (852) 28092197

Author contribution. TPTN obtained data from all species except $L$. fabalis and contributed to data analysis, SHS contributed to sampling Swedish littorinids, MSD, RS and GAW to sampling HK littorinids, DE to Spanish samples, and ER-A contributed to Spanish sampling and data analysis. Developing the MS was led by TPTN, ER-A and GAW and all authors contributed to writing the MS and gave final approval for submission. 


\section{The causal relationship between sexual selection and sexual}

2 size dimorphism in marine gastropods

3

\section{Abstract}

5 Sexual size dimorphism is widespread among dioecious species but its underlying

6 driving forces are often complex. A review of sexual size dimorphism in marine

7 gastropods revealed two common patterns: firstly, sexual size dimorphism, with

8 females being larger than males, and secondly females being larger than males in

9 mating pairs; both of which suggest sexual selection as being causally related with

10 sexual size dimorphism. To test this hypothesis, we initially investigated mechanisms

11 driving sexual selection on size in three congeneric marine gastropods with different

12 degrees of sexual size dimorphism, and, secondly, the correlation between

13 male/female sexual selection and sexual size dimorphism across several marine

14 gastropod species. Male mate choice via mucus trail following (as evidence of sexual

15 selection) was found during the mating process in all three congeneric species,

16 despite the fact that not all species showed sexual size dimorphism. There was also a

17 significant and strong negative correlation between female sexual selection and

18 sexual size dimorphism across 16 cases from seven marine gastropod species. These

19 results suggest that sexual selection does not drive sexual size dimorphism. There 
was, however, evidence of males utilizing a similar mechanism to choose mates (i.e.

21 selecting a female slightly larger than own size) which may be widespread among

22 gastropods, and in tandem with present variability in sexual size dimorphism among

23 species, provide a plausible explanation of the observed mating patterns in marine

24 gastropods.

25

26 Keywords: assortative mating, mate choice, male-male competition, snail, trail

27 following

28

29 Declarations of interest: none

30

31

32

\section{Introduction}

33 Most taxonomic groups of gonochoric animals exhibit sexual size dimorphism, where

34 body size differs between sexes, a pattern which has intrigued evolutionary biologists

35 since Darwin ,2007). In most cases, the male is larger than the

36 female, but there are many exceptions (reviewed in Andersson, 1994). The occurrence

37 of such dimorphism begs the questions of why the sexes should differ in a trait that

38 should be, a priori, strongly correlated between sexes (as every individual has half of 
39 the genome from both parents) and this has provoked a variety of alternative

40 evolutionary explanations (reviewed in Andersson, 1994; Blanckenhorn, 2005;

41 Fairbairn et al., 2007; Shine, 1989). The most common trend, males being larger than

42 females, has often been explained in terms of sexual selection favouring larger males

43 in relation to the female optimum (Blanckenhorn, 2005). The opposite trend, females

44 being larger than males, can be explained as a result of fecundity selection favouring

45 larger sizes in females in relation to the male optimum (Andersson, 1994;

46 Blanckenhorn, 2005). To date, the mutual contribution from multiple selective forces

47 is the most widely accepted explanation for sexual size dimorphism (Anderss 1994;

48 v s Rd gu s O’H W d 2016; but see Blanckenhorn, 2005, for alternative

49 explanations). Nevertheless, it is generally difficult to test these multiple selective

50 forces which may involve evolutionary and ecological/behavioural mechanisms

51 (Blanckenhorn, 2005).

52 Marine gastropods offer several advantages for the study of evolutionary causes

53 of sexual size dimorphism, as in most gastropods females are larger than males

54 (opposite to the general trend in many other animals); and potential behavioural

55 mechanisms for driving sexual selection can be directly measured in the wild. In fact,

56 compared to our current knowledge about reproductive behaviour in vertebrates and 
57 insects, sexual selection and sexual conflict theory have only recently been

58 investigated in marine gastropods (Angeloni, 2003; Evanno, Madec, \&

59 Arnaud, 2005; Johannesson, Saltin, Duranovic, Havenhand, \& Jonsson, 2010; Leonard,

60 1991, 2005). Most marine gastropods are gonochoric and the majority of sexual

61 selection studies have been carried out on species in the family Littorinidae

62 (Erlandsson \& Johannesson, 1994; Erlandsson \& Rolán-Alvarez, 1998; Johannesson et

63 al., 2016; Ng \& Williams, 2014; Rolán-Alvarez \& Ekendahl, 1996; Saur, 1990; Zahradnik,

64 Lemay, \& Boulding, 2008); probably as a result of their wide distribution, high

65 abundance (Reid, 1989; Rolán-Alvarez, Austin, \& Boulding, 2015) and the fact that

66 sexes can be readily identified (Reid, 1986, 1989). There have, however, also been

67 studies on Neptunea arthritica (Lombardo \& Goshima, 2010, 2011; Lombardo,

68 Takeshita, Abe, \& Goshima, 2012) and Rapana venosa (Xue, Zhang, \& Liu, 2016) as well

69 as studies on sexual selection on size in several other species (Table 1).

70 The goal of the present paper is to use marine gastropods as model organisms for

71 understanding the causes of sexual size dimorphism, using direct measurement of

72 mating pairs in the wild to allow natural, in-situ, estimation of sexual selection (and its

73 behavioural mechanism). First, we provide an overview of these findings to integrate

74 and interpret the patterns found in marine gastropods and, second, we propose a 

patterns.

\section{What is the current state of knowledge?}

79 In gonochoric marine gastropods the mating process is often initiated by a male following the mucus trail of a female, and this is the first stage at which selection for

81 size may occur ( $\mathrm{Ng}$ et al., 2013). Size-related mate choice during trail following has, for example, been demonstrated in Littorina saxatilis (Johannesson et al., 2008) with males preferring to follow females larger than themselves. This appears to be a general phenomenon in littorinids, resulting in size-dependent male mate preference (e.g.

85 Littorina fabalis and Littoraria ardouiniana; Ng \& Williams, 2014; Saltin, Schade, \&

86 Johannesson, 2013).

87 In general, males (in gonochoric species) or sperm donors (in hermaphroditic species) tend to mate with females or sperm recipients larger than themselves (Table

89 1). Males also, in general, copulate with larger females for longer durations than with

90 smaller females (Table 1; Erlandsson \& Johannesson, 1994; Hollander, Lindegarth, \&

91 Johannesson, 2005; Saur, 1990). Most species also show sexual size dimorphism, with

92 females being larger than males, but the coincidence between the mating pattern and 
94 where sexes are typically of similar size (Table 1). Interestingly, in one species,

95 Assiminea japonica, the direction of sexual size dimorphism and also the size

96 differences between mated males and females are reversed as compared to other

97 Gastropoda (males being larger than females), suggesting a causal relationship

98 between these patterns (Blanckenhorn, 2005).

99 During copulation, selection occurs via inter-individual interactions. Male-male 100 competition can, for example, occur when a rival male physically challenges a mating 101 male (Gibson, 1965; Ng, Davies, Stafford, \& Williams, 2016; Zahradnik et al., 2008). In 102 a few species, females may reject males, through mechanisms such as pushing away 103 or even biting the penis (e.g. Littorina littorea, Saur, 1990; Neptunea arthritica, 104 Lombardo \& Goshima, 2010); Littoraria melanostoma, Ng \& Williams, 2015), indicating 105 some degree of female influence over choice and male reproductive success. A recent 106 study has also shown that, despite being polyandrous, paternity in Littorina saxatilis is 107 biased towards certain fathers, suggesting the possibility of postcopulatory (perhaps 108 due to sperm competition) sexual selection for male size (Johannesson et al., 2016). 


\section{Sexual selection and size dimorphism}

111 While most studies have been confined to investigate a single mechanism at a single

112 mating stage, usually under laboratory conditions, taken together these studies

113 indicate that sexual selection on size in marine gastropods can occur at a number of

114 different times during the mating process (before, during and after copulation)

115 through a number of different mechanisms (Ng, 2013; Ng \& Williams,

116 2014). The close coincidence between mating pattern and sexual size dimorphism

117 (Table 1) suggests that the mechanism that is driving sexual selection is also

118 contributing to sexual size dimorphism. A similar mechanism has been proposed in

119 black scavenger flies (Sepsis species), where sexual selection acting differentially on

120 males, plus increased fecundity favouring large size in females, contributed to drive

121 sexual size dimorphism (but see alternative explanations reviewed in Blanckenhorn,

122 2005).

123 To investigate why previous studies have shown an association between sexual

124 selection and sexual size dimorphism, we evaluated the mechanisms that may cause

125 male and female size sexual selection across several marine gastropod species.

126 Firstly, we assessed the various behavioural mechanisms of sexual selection

127 throughout the mating process (from trail following to copulation) in three 
128 Echinolittorina species from Hong Kong that differ in their degree of sexual size

129 dimorphism. Secondly, the strength of sexual selection (using standardized selection

130 estimates) on male and female size was investigated in seven littorinid species from

131 two genera (Echinolittorina and Littorina). The methodology used was identical to

132 those employed in previous studies (Erlandsson \& Johannesson, 1994; Erlandsson \&

133 Rolán-Alvarez, 1998; Johannesson, Rolán-Alvarez, \& Ekendahl, 1995; Rolán-Alvarez,

134 Carvajal-Rodríguez, et al., 2015; Rolán-Alvarez, Erlandsson, Johannesson, \& Cruz,

135 1999) to allow a rigorous interspecific comparison of patterns of sexual selection and,

136 importantly, to identify any general patterns among marine gastropods.

137

138 Material and Methods

139 Definitions of sexual selection

140 Sexual selection has been considered a controversial concept since Darwin's definition

141 (Andersson, 1994; Futuyma \& Kirkpatrick, 2016). In this paper, we adhere to the

142 population genetic definition where sexual selection is viewed as a component of

143 natural selection typically being caused, as proposed by Darwin, by two biological

144 mechanisms; mate competition and mate choice (Arnold \& Wade, 1984; Endler, 1986;

145 Lewontin, Kirk, \& Crow, 1968; Merrell, 1950; Rolán-Alvarez, Carvajal-Rodríguez, et al., 
147 on the sex that the competition occurs within (i.e. intrasexual selection), while in

148 contrast, mate choice exerts its selective effects on the opposite sex (i.e. inter-sexual

149 selection). The consequences of sexual selection have, therefore, often been

150 considered at different stages of the reproductive cycle, depending on the study

151 species (reviewed in Andersson, 1994), but typically are subdivided into the pre-

152 copulatory and post-copulatory stages (Eberhard, 1991). In this study, we focus

153 exclusively on pre-copulatory sexual selection (termed sexual selection from now) for

154 practical reasons, although the potential for post-copulatory sexual selection has been

155 established in several gastropod species (Johannesson et al., 2016; Rolán-Alvarez, 156 Austin, et al., 2015).

157

158 Mechanisms of sexual selection in three Echinolittorina species

159 In this study, field measurements of the whole mating process (i.e. from trail following

160 to copulation, see detailed text and video descriptions in Ng \& Williams, 2014) were

161 obtained for Echinolittorina malaccana, E. radiata and E. vidua in JuneJuly (the hot and

162 wet season in Hong Kong, see Kaehler \& Williams, 1996, when sea surface

163 temperatures varied between $27.3-28.4^{\circ} \mathrm{C}$, EPD 2012), 2012 at $\mathrm{C} p$ d' Aguilar Marine 

were visually identified on the shore. If the male subsequently mounted an individual

170 that he followed, copulation duration was measured from the moment the male had

171 positioned himself in the copulation position until he left (see Gibson, 1965, and Saur,

172 1990). Although it is extremely difficult to see the insertion of the penis into the

173 female's cavity in situ, the period during which a male remained in the copulation

174 position is considered a reliable estimate of copulation duration (Saur, 1990). Females

175 appeared to have no strategies to reject males during these stages; either through

176 preventing males from following their trails or from copulating with them (e.g. such as

177 the rejection behaviour displayed by Littoraria melanostoma, $\mathrm{Ng}$ \& Williams, 2015)

178 and, in most cases, the females continued to move and feed on the rock surface. Given

179 this lack of response by the females, we assume any variation in frequency of 180 mounting and/or copulation duration among females of different sizes was solely a 181 result of male mate choice. Finally, all pairs 
182 (Echinolittorina malaccana: $n=53$; E. radiata: $n=56$; E. vidua: $n=43$ ) were collected

183 after copulation, sexed and their shell lengths $( \pm 0.1 \mathrm{~mm})$ measured using vernier

184 callipers in the laboratory.

185 To determine if there was mate choice based on snail size during trail following

186 and consequent mounting, we tested if pairs with female size > male size were more

187 frequent than pairs with male size > female size using a Chi-square test. In addition, as

188 an indication of male mate choice during copulation, tud t's t-tests were conducted

189 to compare the copulation duration of snails in these two categories, and multiple

190 regression was used to investigate the relative contribution of male and female size to

191 the observed variation in copulation duration.

193 Strength of sexual selection in seven littorinid species

194 To test for generality in the patterns of sexual selection on size, we used published

195 material from Littoraria flava, Littorina saxatilis (Cardoso, Costa, \& Loureiro, 2007;

196 Erlandsson \& Rolán-Alvarez, 1998), and Echinolittorna malaccana and E. radiata (Ng

197 et al., 2016). In this study, we also incorporated unpublished data from 
205 The distance of these reference snails to the mating pair depended on snail density

206 and was within a $25-\mathrm{cm}$ radius for Echinolittorina malaccana, E. radiata, E. vidua,

207 Littorina littorea and L. saxatilis, and within 10-cm for L. fabalis. The mating pairs and 208 reference snails were returned to the laboratory where species, sex and size (as 209 described above) were recorded. Sexual size dimorphism was investigated using two-t $d$ tud t's $t$-tests (using all

211 mating and reference individuals), and deviation from a 1:1 sex ratio was examined

212 using binomial tests (again using all the reference snails). The sexual selection intensity

213 index (standardized selection differential; SS), was used to compare the strength of 214 sexual selection between different populations (see Arnold \& Wade, 1984; Falconer \& 215 Mackay, 1996). SS on male and female size was measured as the mean size of the 
216 mating males or females minus the mean size of reference males or females, divided

217 by the standard deviation of the size of reference males or females $\left(\mathrm{SS}_{\mathrm{m}}\right.$ or $\mathrm{SS}_{\mathrm{f}}$; see

218 Cardoso et al., 2007; Erlandsson \& Rolán-Alvarez, 1998).

219 Sexual selection on size was tested by one-way ANOVA using the fixed factor mating

220 (mated or reference individuals) for each sex separately, with juvenile snails (either

221 with immature sexual organs or smaller than adult size (following Erlandsson \& Rolán-

222 Alvarez, 1998; Mak, 1996) excluded from the analyses.

224 Dimorphism and sexual selection, how are they related?

225 To investigate the possible causal relationship between male/female sexual selection

226 and sexual size dimorphism in marine gastropods we propose two alternative

227 evolutionary scenarios with subsequent predictions that can be empirically tested as

228 follows:

229 1) The first scenario is that sexual size dimorphism is just a consequence of male

230 sexual selection [see Blackernhorn 2005]. This would occur if fecundity selection

231 would always favour larger females, but sexual selection would favour larger males

232 only in certain cases (resulting in a low level of sexual size dimorphism). Under this

233 scenario a high level of sexual size dimorphism would occur exclusively when sexual 
234 selection does not favour larger males (see Fig. 1). This mechanism, if it occurs in most

235 gastropod species, would predict a negative correlation between male sexual

236 selection $\left(\mathrm{SS}_{\mathrm{m}}\right)$ and sexual size dimorphism. A variation of this explanation would be

237 that sexual selection in both sexes is the main driver of sexual size dimorphism (see

238 Blanckenhorn, 2005). In that case, differential sexual selection between sexes (i.e. SS

$239>\mathrm{SS}_{\mathrm{m}}$ ), would result in female size being systematically larger than male size (Fig. 1).

240 We would, therefore, expect a positive correlation between differential sexual

241 selection $\left(\mathrm{SS}_{\mathrm{f}-\mathrm{m}}=\mathrm{SS}_{\mathrm{female}}-\mathrm{SS}_{\mathrm{male}}\right.$; or $\left.\mathrm{SS}_{\mathrm{f}}\right)$ and sexual size dimorphism across populations

242 and species.

243 2) A second evolutionary scenario is that sexual size dimorphism is pre-existing

244 and responsible for present-day levels of sexual selection, but we do not propose any

245 specific explanation for the sexual size dimorphism (as it could be caused by other

246 components of natural selection). A possible example of such a situation is when

247 differences in survivorship between sexes for size exist, causing different optima in

248 male and female size (see Blanckenhorn. 2005). Under this scenario, we propose that

249 the species-specific level of sexual selection is a consequence of certain mate choices

250 in tandem with pre-existing species-specific sexual size dimorphism. In gastropods and

251 most other species, there is positive assortative mating for size (Jiang, Bolnick, \& 
252 Kirkpatrick, 2013), which suggests mate choice may be based on a 'similarity-like'

253 mechanism (Fernández-Meirama et al., 2017). If such similarity would be displaced

254 from the male optimum, for example if a male prefers to mate with a female of similar

255 size to himself (plus a certain constant value; as females are typically larger than males

256 in mating pairs, Table 1), then such a mechanism would result in a negative correlation

257 between $\mathrm{SS}_{\mathrm{f}}\left(\right.$ and $\mathrm{SS}_{\mathrm{f}-\mathrm{m}}$ ) and sexual size dimorphism

258 (see explanation in Fig. 1). Interestingly, this prediction would never affect the

259 relationship between $\mathrm{SS}_{\mathrm{m}}$ and sexual size dimorphism, as male mate choice will affect

$260 \mathrm{SS}_{\mathrm{f}}$ but not $\mathrm{SS}_{\mathrm{m}}$.

261 The above two scenarios can only be tested when the same mechanism is prevalent

262 for most species, and if this is not the case, we would expect no correlation between

263 sexual selection and sexual size dimorphism. Using data from the seven studied

264 species (and several populations within each species), we tested these alternative

265 hypotheses for sexual selection (i.e. SS) and sexual size dimorphism (Table 2). Both

266 standardized and raw sexual size dimorphism value data were investigated, but as the

267 results were statistically very similar, we only present the standardized sexual size

268 dimorphism values. Spearman's correlation coefficient (rho) and corresponding 
270 size dimorphism relationship using SPSS 23.0 (SPSS Inc., Chicago, IL, U.S.A).

\section{Ethical note}

273 All individuals used were captured from non-endangered populations with high

274 densities and with corresponding permission of local authorities (Xunta de Galicia and

275 the Agriculture, Fisheries and Conservation Department, Hong Kong SAR

276 Government). In addition, due to the proximity of the sampling sites to the Swire

277 Institute of Marine Science, individuals of Echinolittorina spp. were captured,

278 measured in the laboratory and returned alive to the sampling sites; while the

279 remaining species which were collected from distant sites, were transported to the

280 laboratory and then anesthetized (by cold temperature) before submersion in

281 alcohol.

\section{Results}

284 Interspecific sexual selection mechanisms with varying size dimorphism

285 All cases (152) of trail following, except one, consisted of a male following a female 286 trail (i.e. females rarely followed trails to mate). Instances of males following a trail of 
287 a different species were also rare (Echinolittorina malaccana, 6 out of 53 cases; $E$.

288 radiata, 6 out of 56 cases, representing $\sim 11 \%$ of cases for both species; $E$. vidua, 0 out

289 of 43 cases), and in only half of these false trail-followings did the male subsequently

290 mount and take up the copulation position. This suggests that males can recognize and

291 differentiate the species laying the mucus trail, as well as between male and female

292 mucus trails as they trail-followed and mounted many more females than expected by

293 chance (Table 3). Most conspecific mountings (>93\%) resulted in copulations, but in a

294 few cases (E. malaccana, one case; E. radiata and E. vidua, two cases each) a male

295 mounted a conspecific female without copulation, and in four of these five cases (80\%)

296 the female was much smaller $(2.3-3.3 \mathrm{~mm}$ or $32-37 \%$ smaller $)$ than the male. All

297 species showed a significantly higher frequency of males following a larger female

298 (than their own sizes) than expected by chance (Fig. 2a), suggesting a similar size-

299 dependent male mate preference during trail following (see Table 3). The same

300 mechanism, therefore, seems to be present in the three species despite their

301 differences in sexual size dimorphism.

302 Males did not, however, copulate for significantly longer with females larger than

303 themselves as compared to females smaller than themselves, with the exception of

304 Echinolittorina vidua. Differential copulation duration can, therefore, only be 
$307 d f=35, P<0.05$, Fig. $2 b)$, which is the only species which did not exhibit sexual size dimorphism. Copulation duration, therefore, seems to be related to female rather than male size (Table 4).

\section{Strength of sexual selection with varying size dimorphism}

312 Mated females were typically larger than unmated females (indicating positive sexual

313 selection on female size), and in 13 out of 16 (>80\%) comparisons these differences

314 were significant (Table 2). In males the strength of sexual selection was generally

315 weaker, less clear, and species dependant (only 7 out of 16 (44\%) comparisons were

316 significant, Table 2). There were similar, positive, sexual selection indices for both

317 sexes in Echinolittorina malaccana, E. radiata, Littorina fabalis and the sheltered

318 ecotype of $L$. saxatilis (Table 2). For the wave ecotype of L. saxatilis the sexual selection

319 indices were negative, indicating smaller females were selected by males, although

320 this was only significant in one population (Table 2). Apart from this one exception,

321 the overall trend in the family Littorinidae was for positive sexual selection on size in 
322 both sexes of the seven species (including the sheltered ecotype of L. saxatilis, Table

3232 , overall standardized means \pm SD: males $=0.27 \pm 0.153$; females $=0.32 \pm 0.083$ ).

325 The relationship between sexual selection and size dimorphism

326 Overall, the relationship between $\mathrm{SS}_{\mathrm{f}}\left(\right.$ and $\mathrm{SS}_{\mathrm{f}-\mathrm{m}}$ ) and sexual size dimorphism was

327 highly negative and significant across the whole data set (Table 2, rhof $=-0.77, d f=15$,

$328 P=0.001$, Fig. 3; rhof-m $=-0.56, d f=15, P=0.025)$. The same trend was observed using

329 the mean values within species ( $\mathrm{rho}_{\mathrm{f}}=-0.89, d f=6, P=0.007$, Fig. 3 ; rhof $_{\mathrm{f}}=-0.79, d f=$

$3306, P=0.036$ ) or using the seven species but maintaining the two L. saxatilis ecotypes

331 separately ( rho $_{f}=-0.71, d f=7, P=0.047$; hoof-m $=-0.74, d f=7, P=0.037$ ). All these results

332 are in full agreement with expectations from scenario 2 (i.e. sexual size dimorphism

333 was pre-existing and not driven by sexual selection but other components of natural

334 selection). The relationship between $\mathrm{SS}_{\mathrm{m}}$ and sexual size dimorphism, however,

335 showed a pattern contrary to scenario 1, but compatible with scenario 2 (see Fig. 1;

336 rho $_{\text {samples }}=-0.14, d f=15, P=0.613$, rho $_{\text {species }}=0.21, d f=6, P=$

$3370.645)$ 


\section{Discussion}

340 Marine gastropods show sexual size dimorphism with, typically, the female being

341 larger than the male, which represents the opposite trend to many other gonochoric

342 species studied to date (Andersson, 1994; Blanckenhorn, 2005; Fairbairn et al., 2007).

343 Such a general, but unconventional, pattern should be particularly informative for our

344 understanding of the causes of sexual size dimorphism (see arguments in

345 Blanckenhorn, 2005). In marine gastropods, males also mate with females typically

346 larger than themselves and, even in hermaphroditic species, sperm donors generally

347 mate with larger sperm recipients (Table 1). We found no obvious link between any

348 life history traits and sexual size dimorphism, except that the relationship between

349 patterns of mating and sexual dimorphism may suggest a causal link between sexual

350 selection and size dimorphism as described in several studies (Blanckenhorn, 2005;

351 Rohner, Blanckenhorn, \& Puniamoorthy, 2016, and references therein).

352 Our results showed clear support for the second proposed scenario, that the

353 observed sexual size dimorphism in many marine gastropods was pre-existing and not

354 necessarily driven by sexual selection. In addition, male and female sexual selection

355 was found in many marine gastropods and may be caused by the existence of a

356 common mate choice mechanism (males preferentially mate with females of the same

357 size plus a specific value, .. 's m t - 'm sm Fernández-Meirama et al., 2017), 
358 and such mechanism would produce a negative correlation between female (but not

359 male) sexual selection and sexual size dimorphism. This finding suggests that it is the

360 degree of sexual dimorphism which explains the observed patterns in female sexual

361 selection. The same relationship between these two variables is observed even when

362 there are populations and species that exhibit the opposite trends in sexual selection

363 or sexual size dimorphism, confirming the generality of the trend. Under this scenario,

364 species that have the largest size dimorphism, even when males prefer to mate with

365 larger females than themselves, could effectively still choose relatively small females

366 (i.e. still larger than the male) from the overall female population (see Fig. 1). When

367 we studied the mechanism of sexual selection in Echinolittorina species with different

368 levels of sexual size dimorphism in the wild, we observed the same mechanism of male

369 choice causing female sexual selection, confirming that sexual selection cannot explain

370 present levels of sexual size dimorphism.

371 In addition to sexual selection, other selection forces can also contribute to shape

372 size traits in these snails and different selection pressures may frequently counteract

373 each other (Blanckenhorn, 2005). Fecundity selection, for example, favours large size

374 in females (larger females carry more eggs or offspring, Hughes \& Answer, 1982; Ng \&

375 Williams, 2012; Ross \& Berry, 1991; Zahradnik et al., 2008), but variability selection 
377 al., 2008). Another scenario could be that male gastropods achieve a smaller size compared to females just because of differential daily activities, as searching for mates

379 has been considered to impose a large daily energetic cost, while females focus 380 preferentially on foraging and feeding (Ng et al., 2013; Rolán-Alvarez, Austin, et al., 3812015 ; Zahradnik et al., 2008), causing differential growth rates between sexes (Riascos $382 \&$ Guzman, 2010). Distinct natural selection components or life-history traits may, 383 therefore, act differentially on males and females to drive sexual size dimorphism in 384 marine gastropods, without the need to invoke any role of sexual 385 selection.

386 Another possibility would be that the observed sexual dimorphism does not have a

387 genetic basis. It is, for example, unknown whether differences in male and female 388 body sizes in gastropods are genetic in origin. Differential ecological strategies 389 between sexes could, therefore, affect the probability of survivorship at different sizes, 390 or affect the size at adult age or growth rate differences between sexes as recorded in 391 some pulmonates (Sutton, Zhao, \& Carter, 2017). The niche hypothesis, which includes 392 the former possibility, has previously been proposed as a general explanation for 393 sexual size dimorphism (Shine, 1989), but it is rather difficult to test, as the ecological 
conditions experienced may substantially vary from one organism to another.

395 However, this phenotypic version of the niche hypothesis assumes that body size

396 differences between sexes are not genetic in origin, and this prediction could be

397 experimentally tested.

On the other hand, both male and female sexual selection has been detected in

399 many marine gastropods. Male mate choice in littorinids appears to be initiated at the

400 trail following stage, where males generally follow mucus trails laid by females larger

401 than themselves (this study, Ng \& Williams, 2014; Saltin et al., 2013). It can be argued

402 that this finding may be partially due to a higher probability of encountering larger

403 females, as females are generally larger than males (but see statistical test from Table

404 3). The same trend was, however, also found in Echinolittorina vidua which shows no

405 size sexual dimorphism. Further evidence of males having a preference for somewhat

406 larger females is provided from other littorinid species where a size-dependent male

407 mate preference was demonstrated in laboratory choice experiments (Erlandsson \&

408 Kostylev, 1995; Johannesson et al., 2008; Ng \& Williams, 2014), supporting the theory

409 that males have the ability to assess the size of females from their trails. This variety

410 of evidence, together with the correlation between sexual selection and size

411 dimorphism found in all studied species, suggests that there could be a conserved 
413 slightly larger than themselves, causing the observed trend for sexual selection in

414 females across species.

$416 \mathrm{t}$ g st $\mathrm{f} m$ ?' Selecting the largest available female may, in fact, not necessarily be

417 advantageous for a male because of the risk of sperm competition (Herdman, Kelly, \&

418 Godin, 2004; Wedell, Gage, \& Parker, 2002). Any fecundity-related benefits accruing

419 to a male that has mated with a large female may be offset by an associated fitness

420 cost of shared paternity if large females are more likely to be mated multiple times

421 (Herdman et al., 2004). A m 's st $t g$ f selecting females slightly larger than his own

422 size during trail following may, therefore, have an important implication for

423 maximizing reproductive success through investing in a range of larger females rather

424 than the largest female available (Widemo \& Sæther, 1999). Another plausible reason

425 can be related to physical mating constraints, such that copulation becomes physically

426 more difficult for two individuals when their size difference exceeds a certain

427 threshold (Arnqvist, Rowe, Krupa, \& Sih, 1996; Crespi, 1989). Size-dependent male

428 mate preference during trail following can, therefore, be a strategy driven by a balance

429 between a set of fitness costs and benefits (Herdman et al., 2004; Wedell et al., 2002). 
430 Empirical and simulation studies will, however, be necessary to confirm this

431 interpretation.

432 The male sexual selection pattern ( $\mathrm{SS}_{\mathrm{m}}$ from Table 2), on the other hand, can be

433 caused by male-male competition. Aggressive physical male-male contests, for

434 example, have been reported in E. malaccana and E. radiata ( $\mathrm{Ng}$ et al., 2016) as well

435 as in several other littorinids (Gibson, 1965; Ng \& Williams, 2014; Zahradnik et al.,

436 2008) and other marine gastropods (e.g. Strombus pugilis, Bradshaw-Hawkins and

437 Sander 1981). In the littorinid species where such contests were observed, larger m s

$438 \mathrm{~m} \quad \mathrm{ft} \quad \mathrm{w}$ t $\mathrm{s}$ 'm $\mathrm{tg}$ tt $\mathrm{s}^{\prime} \mathrm{w}$ t $\mathrm{sm} \quad \mathrm{m} \quad \mathrm{s}$ pu $\mathrm{t} \mathrm{g}$ with females were displaced

439 (Ng et al., 2016; Ng \& Williams, 2014).

440 Smaller males copulated for longer than larger males in Echinolittorina radiata, which

441 may be interpreted as a form of 'prudent choice' (Fawcett \& Johnstone, 2003), where

442 smaller males may be more judicious in investing their sperm due to the potentially

443 greater time and energy sts $f \mathrm{~s} \mathrm{~g}^{\prime} \mathrm{mt} g$ tt $\mathrm{s}^{\prime} \mathrm{t} g \mathrm{~m}$ s. Previous work has shown

444 that larger males were able to assess the size of their rivals and attack smaller rivals in

445 E. radiata, but not E. malaccana (Ng et al., 2016).

446 Copulating for longer could, therefore, be advantageous (in terms of fertilization

447 success) for smaller males when mating opportunities can be limited in comparison to 
448 larger males. Further investigations into variation in male mate preference under

449 different levels of male-male competition are, however, needed to formally test this

450 hypothesis (see Franceschi, Lemaître, Cézilly, \& Bollache, 2010).

\section{Conclusion}

Our study shows that there is a negative relationship between sexual selection

454 and sexual size dimorphism across many marine gastropod species, indicating that

455 such size dimorphism is unlikely to be produced by the mechanisms contributing to

456 sexual selection. Nevertheless, a common male mate choice (i.e. selecting a mate

457 slightly larger than their own body sizes) seems to explain the female sexual selection

458 observed in most studied marine gastropods. The level of size dimorphism along with

459 the size-dependent male mate preference may, therefore, explain the pattern of 460 sexual selection in marine gastropods. Such an apparently highly conserved

461 mechanism of mate choice in this diverse taxonomic group suggests that there may be

462 an important canalization of the mechanical/physiological traits used to search for

463 mates during reproduction, which may reflect the constraints imposed by the way the

464 snails move, and the multi-functional benefits of utilizing their mucus trails when

465 searching for a mating partner (Ng et al., 2013). 
468 dimorphism, particularly as most studies do not compare multiple species with the 469 same methodologies. Although the question of why females are larger than males in

470 gastropods remains unresolved, we have provided evidence to support a better

471 understanding of the causal and consequential relationships between sexual size

472 dimorphism and sexual selection in this large but under studied taxon.

473

474 Data accessibility

475 The data used for this study has been deposited in Dryad

476 (doi:10.5061/dryad.h214h8t; DATA NG et al 2018).

479 References

480 Andersson, M. B. (1994). Sexual selection. Princeton: Princeton University Press.

481 Angeloni, L. (2003). Sexual selection in a simultaneous hermaphrodite with 482 hypodermic insemination: body size, allocation to sexual roles and paternity. Animal Behaviour, 66(3), 417-426. https://doi.org/10.1006/anbe.2003.2255 
484 485 486 487 488 489 490 491 492 493 494 495 496 497 498 499 500 501 502 Angeloni, L., \& Bradbury, J. (1999). Body size influences mating strategies in a simultaneously hermaphroditic sea slug, Aplysia vaccaria. Ethology Ecology \& Evolution, 11(2), 187-195. https://doi.org/10.1080/08927014.1999.9522836

Arnold, S. J., \& Wade, M. J. (1984). On the Measurement of Natural and Sexual Selection. Evolution, 38(4), 720-734. https://doi.org/10.2307/2408383

Arnqvist, G., Rowe, L., Krupa, J. J., \& Sih, A. (1996). Assortative mating by size: A metaanalysis of mating patterns in water striders. Evolutionary Ecology, 10(3), 265284. https://doi.org/10.1007/BF01237684

Avaca, M. S., Narvarte, M., \& Martín, P. (2012). Size-assortative mating and effect of maternal body size on the reproductive output of the nassariid Buccinanops globulosus. Journal of Sea Research, 69, 16-22. https://doi.org/10.1016/j.seares.2012.01.003

Avaca, M. S., Narvarte, M., \& Martín, P. (2013). Age, growth and mortality in

$$
\begin{aligned}
& \text { Buccinanops globulosus (Gastropoda: Nassariidae) from Golfo } \\
& \text { Nuevo (Argentina). Marine Biology Research, } 9(2), \\
& \text { 208-219. }
\end{aligned}
$$

https://doi.org/10.1080/17451000.2012.708420

Blanckenhorn, W. U. (2005). Behavioral Causes and Consequences of Sexual Size Dimorphism.

Ethology,

1016(11), 977-1016. 
504 Bradshaw-Hawkins, V. I., \& Sander, F. (1981). Notes on the reproductive biology and 505 behavior of the West Indian fighting conch, Strombus pugilis Linnaeus in Barbados, with evidence of male guarding. The Veliger, 24, 159-164. http://www.biodiversitylibrary.org/part/93783

508

509

510

Cardoso, R. S., Costa, D. S., \& Loureiro, V. F. (2007). Mating behaviour of the marine snail Littoraria flava (Mollusca: Caenogastropoda) on a boulder shore of southeast Brazil. Journal of the Marine Biological Association of the UK, 87(4), 947952. https://doi.org/10.1017/S0025315407053210

Crespi, B. J. (1989). Causes of assortative mating in arthropods. Animal Behaviour, 38(6), 980-1000. https://doi.org/10.1016/S0003-3472(89)80138-1

Davies, M., \& Beckwith, P. (1999). Role of mucus trails and trail-following in the behaviour and nutrition of the periwinkle Littorina littorea. Marine Ecology Progress Series, 179, 247-257. https://doi.org/10.3354/meps179247

Eberhard, W. G. (1991). Copulatory courtship and cryptic female choice in insects. Biological Reviews, 66(1), 1-31. https://doi.org/10.1111/J.1469185X.1991.TB01133.X

521 Endler, J. A. (1986). Natural selection in the wild. Princeton, New Jersey: Princeton 
University Press.

523 Erlandsson, J., \& Johannesson, K. (1994). Sexual selection on female size in a marine

524

525

526

527

528

529

530

531

532

533

534

535 sexual selection in a hermaphrodite: What influences sperm precedence in the garden

536 snail Helix aspersa? Molecular Ecology, 14(3), 805-812.

537 https://doi.org/10.1111/j.1365-294X.2005.02449.x

538 Fairbairn, D. J., Blanckenhorn, W. . , T. (2007). Sex, size, and gender roles:

539 evolutionary studies of sexual size dimorphism. Oxford: Oxford University Press.

540 Falconer, D. S., \& Mackay, T. F. C. (1996). Introduction to Quantitative Genetics. New 
York: Longman.

542 Fawcett, T. W., \& Johnstone, R. A. (2003). Mate choice in the face of costly

$$
\text { competition. }
$$

Behavioral

Ecology,

14(6),

771-779.

544 https://doi.org/10.1093/beheco/arg075

545

Fernández-Meirama, M., Estévez, D., Ng, T. P. T., Williams, G. A., Carvajal-Rodríguez,

Franceschi, N., Lemaître, J. F., Cézilly, F., \& Bollache, L. (2010). Size-assortative pairing A., \& Rolán-Alvarez, E. (2017). A novel method for estimating the strength of positive mating preference by similarity in the wild. Ecology and Evolution, 7, 11. https://doi.org/10.1002/ece3.2835

in Gammarus pulex (Crustacea: Amphipoda): a test of the prudent

choice hypothesis. Animal Behaviour, 79(4), 911-916.

553 Futuyma, D. J., \& Kirkpatrick, M. (2016). Evolution. Oxford: Oxford University Press.

554 Gibson, D. G. (1965). Mating behaviour in Littorina planaxis Philippi (Gastropoda: Prosobranchiata). The Veliger, 7, 134-139.

556 Herdman, E. J. E., Kelly, C. D., \& Godin, J. G. J. (2004). Male Mate Choice in the Guppy 557 (Poecilia reticulata): Do Males Prefer Larger Females as Mates? Ethology, 
559 Hollander, J., Lindegarth, M., \& Johannesson, K. (2005). Local adaptation but not geographical separation promotes assortative mating in a snail. Animal Behaviour, 70(5), 1209-1219. https://doi.org/10.1016/j.anbehav.2005.03.014

562 Hughes, R. N., \& Answer, P. (1982). Growth, spawning and trematode infection of Littorina littorea (L.) from an exposed shore in North Wales. Journal of https://doi.org/10.1093/oxfordjournals.mollus.a065654

566 Hull, S. L. (1998). Assortative mating between two distinct micro-allopatric populations of Littorina saxatilis (Olivi) on the northeast coast of England. Hydrobiologia, 378(1/3), 79-88. https://doi.org/10.1023/A:1003237521419

569 Ito, A., \& Wada, S. (2006). Intrasexual copulation and mate discrimination in a population of Nodilittorina radiata (Gastropoda: Littorinidae). Journal of Ethology, 24(1), 45-49. https://doi.org/10.1007/s10164-005-0159-1

572 Jiang, Y., Bolnick, D. I., \& Kirkpatrick, M. (2013). Assortative mating in animals. The 573 American Naturalist, 181(6), 125-138. https://doi.org/10.1086/670160

574 Johannesson, K., Havenhand, J. N., Jonsson, P. R., Lindegarth, M., Sundin, A., \& 

assortative mating in a marine snail species. Evolution, 62(12), 3178-3184. https://doi.org/10.1111/j.1558-5646.2008.00510.x

578 Johannesson, K., Rolán-Alvarez, E., \& Ekendahl, A. (1995). Incipient reproductive isolation between two sympatric morphs of the intertidal snail Littorina saxatilis. Evolution, 49(6), 1180-1190. https://doi.org/10.2307/2410443

581

Johannesson, K., Saltin, S. H., Charrier, G., Ring, A. K., Kvarnemo, C., André, C., \& 585

589 Kaehler, S., \& Williams, G. A. (1996). Distribution of algae on tropical rocky shores: spatial and temporal patterns of non-coralline encrusting algae in Hong Kong. 
592 Kurata, K., \& Kikuchi, E. (2000). Comparisons of life-history traits and sexual 593 dimorphism between Assiminea japonica and Angustassiminea castanea

594 (Gastropoda: Assimineidae). Journal of Molluscan Studies, 66, 177-196. $595 \quad$ https://doi.org/10.1093/mollus/66.2.177

596 Leonard, J. L. (1991). Sexual Conflict and the Mating Systems of Simultaneously 597 Hermaphroditic Gastropods. American Malacological Bulletin, 9(1), 45-58. $598 \quad$ http://biostor.org/reference/143261

599 L d J. L. 2005). t m 's p p dsmut us $\mathrm{mp} d \mathrm{ds}$ : A paradox. Integrative and 600 Comparative Biology, 45(5), 856-873.

$601 \quad$ https://doi.org/10.1093/icb/45.5.856

602 Lewontin, R., Kirk, D., \& Crow, J. (1968). Selective mating, assortative mating, and 603 inbreeding: definitions and implications. Eugenics Quarterly, 15(2), 141-143. $604 \quad$ https://doi.org/10.1080/19485565.1968.9987764

605 Lombardo, R. C., \& Goshima, S. (2010). Female copulatory status and male mate choice 606 in Neptunea arthritica (Gastropoda: Buccinidae). Journal of Molluscan Studies, 607 76(4), 317-322. https://doi.org/10.1093/mollus/eyq015

608 Lombardo, R. C., \& Goshima, S. (2011). Sexual conflict in Neptunea arthritica: the 609 power asymmetry and female resistance. Journal of the Marine Biological 610 Association of the UK, 91(01), 251-256. 
612

Lombardo, R. C., Takeshita, F., Abe, S., \& Goshima, S. (2012). Mate choice by males and paternity distribution in offspring of triple-mated females in Neptunea arthritica (gastropoda: Buccinidae). Journal of Molluscan Studies, 78(3), 283-

$$
\text { 289. https://doi.org/10.1093/mollus/eys010 }
$$

Mak, Y. M. (1996). The ecology of the high-zoned littorinids, Nodilittorina trochoides, N. radiata and N. vidua, on rocky shores in Hong Kong (Doctoral dissertation). Hong Kong: University of Hong Kong.

Merrell, D. (1950). Measurement of sexual isolation and selective mating. Evolution, 4(4), 326-331. https://doi.org/10.2307/2405599

Ng, T. P. ., Saltin, S. H., Davies, M. S., Johannesson, K., Stafford, R., \& Williams, G. A. (2013). Snails and their trails: The multiple functions of trail-following in gastropods. Biological Reviews of the Cambridge Philosophical Society, 88(3), 683-700. https://doi.org/10.1111/brv.12023

Ng, T. P. ., \& Williams, G. A. (2012). Contrasting reproductive traits in two species of mangrove-dwelling littorinid snails in a seasonal tropical habitat. Invertebrate Biology, 131(3), 177-186. https://doi.org/10.1111/j.1744-7410.2012.00269.x 
628 Ng, T. P. ., \& Williams, G. A. (2015). Penis-rejection in a mangrove littorinid snail: Why do females reject males? Journal of Molluscan Studies, 81(1), 164-166.

630 https://doi.org/10.1093/mollus/eyu074

$631 \mathrm{Ng}, \mathrm{T}$. P. T. (2013). Reproductive traits and sexual selection in the mangrove littorinid 632 snails, Littoraria ardouiniana and L. melanostoma. Hong Kong: University of

633 Hong Kong.

634

635

636

638

640 Association with Size-Assortative Mating in a Mangrove Snail, Littoraria
ardouiniana. Ethology, 120(10), 995-1002. https://doi.org/10.1111/eth.12271 Association with Size-Assortative Mating in a Mangrove Snail, Littoraria
ardouiniana. Ethology, 120(10), 995-1002. https://doi.org/10.1111/eth.12271

Ng, T. P. T., \& Williams, G. A. (2014). Size-Dependent Male Mate Preference and its Otsuka, C., Yves, R., \& Tobach, E. (1980). A possible relationship between size and reproductive behavior in a population of Aplysia punctata (Cuvier, 1803). The Veliger, 23(2), 159-162. http://biostor.org/reference/128754

Pal, P., Erlandsson, J., \& Sköld, M. (2006). Size-assortative mating and non-reciprocal copulation in a hermaphroditic intertidal limpet: Test of the mate availability hypothesis. Marine Biology, 148(6), 1273-1282. 
647

648

649

650

651

652

653

654

655

656

657

658

659

660

661

662

663

664

Reid, D. G. (1986). The littorinid molluscs of mangrove forests in the Indo-Pacific region: the genus Littoraria. London: British Museum (Natural History).

Reid, D. G. (1989). The comparative morphology, phylogeny and evolution of the gastropod family Littorinidae. Philosophical Transactions of the Royal Society of London. Series B, Biological Sciences, 324(1220), 1-110. https://doi.org/10.1098/rstb.1989.0040

Riascos, J. M., \& Guzman, P. A. (2010). The ecological significance of growth rate, sexual dimorphism and size at maturity of Littoraria zebra and L. variegata (Gastropoda: Littorinidae). Journal of Molluscan Studies, 76(3), 289-295. https://doi.org/10.1093/mollus/eyq011

Rohner, P. T., Blanckenhorn, W. U., \& Puniamoorthy, N. (2016). Sexual selection on male size drives the evolution of male-biased sexual size dimorphism via the prolongation of male development. Evolution, 70(6), 1189-1199. https://doi.org/10.1111/evo.12944

Rolán-Alvarez, E., Austin, C. J., \& Boulding, E. G. (2015). The Contribution of the Genus Littorina to the Field of Evolutionary Ecology. Oceanography and Marine Biology: An Annual Review, 53, 157-214. http://www.crcnetbase.com/doi/abs/10.1201/b18733-6 
665 Rolán-Alvarez, E., \& Caballero, A. (2000). Estimating sexual selection and sexual 666 isolation effects from mating frequencies. Evolution, 54(1), 30-36. https://doi.org/10.1111/j.0014-3820.2000.tb00004.x

668 Rolán-Alvarez, E., Carvajal-Rodríguez, A., de Coo, A., Cortés, B., Estévez, D., Ferreira, 669 M. ... Briscoe, A. D. (2015). The scale-of-choice effect and how estimates of 670 assortative mating in the wild can be biased due to heterogeneous samples.

672 Rolán-Alvarez, E., \& Ekendahl, A. (1996). Sexual selection and non-random mating for 673 shell colour in a natural population of the marine snail Littorina mariae

$674 \quad$ (Gastropoda: $\quad$ Prosobranchia). Genetica, $\quad 97(1), \quad$ 39-46. 675 https://doi.org/10.1007/BF00132579

676 Rolán-Alvarez, E., Erlandsson, J., Johannesson, K., \& Cruz, R. (1999). Mechanisms of 677 incomplete prezygotic reproductive isolation in an intertidal snail: testing 678 behavioural models in wild populations. Journal of Evolutionary Biology, 12(5), 679 879-890. https://doi.org/10.1046/j.1420-9101.1999.00086.x

680 Ross, B., \& Berry, A. J. (1991). Annual and lunar reproductive cycles in Littorina saxatilis 681 (Olivi) and differences between breeding in the marine firth of forth and the 
682

683

684

685

686

687

688

689

690

691

692

693

694

695

696

697

698

699

700

forth estuary. Journal of Molluscan Studies, 57(3), 347-358. https://doi.org/10.1093/mollus/57.3.347

Saltin, S. H., Schade, H., \& Johannesson, K. (2013). Preference of males for large females causes a partial mating barrier between a large and a small ecotype of Littorina fabalis (W. Turton, 1825). Journal of Molluscan Studies, 79(2), 128132. https://doi.org/10.1093/mollus/eyt003

Saur, M. (1990). Mate discrimination in Littorina littorea (L.) and Littorina saxatilis (Olivi) (Mollusca: Prosobranchia). Hydrobiologia, 193, 261-270. https://doi.org/10.1007/BF00028082

R. 1989). $E$ g C ussf $t$ Ev ut $f$ xu $D m p$ sm: A R v w of the Evidence. The Quarterly Review of Biology, 64(4), 419-461. https://doi.org/10.2307/2830103

Sutton, K. L., Zhao, L., \& Carter, J. (2017). The estimation of growth dynamics for Pomacea maculata from hatchling to adult. Ecosphere, 8(7), e01840. https://doi.org/10.1002/ecs2.1840

Svenson, G. J. . K. R d gu S H. M. O'H J.C. W d . 2016). Selection for predation, not female fecundity, explains sexual size dimorphism in the orchid mantises. Scientific Reports, 6(1), 37753. https://doi.org/10.1038/srep37753 
701 Wedell, N., Gage, M. J. G., \& Parker, G. A. (2002). Sperm competition, male prudence

702

703

704

705

706

707

708

709

710

711

712

713

714

715

716

717

and sperm-limited females. Trends in Ecology and Evolution, 17(7), 313-320.

https://doi.org/10.1016/S0169-5347(02)02533-8

Widemo, F., \& Sæther, S. A. (1999). Beauty is in the eye of the beholder: Causes and consequences of variation in mating preferences. Trends in Ecology and Evolution, 14(1), 26-31. https://doi.org/10.1016/S0169-5347(98)01531-6

Xue, D.-X., Zhang, T., \& Liu, J.-X. (2016). Influences of population density on polyandry and patterns of sperm usage in the marine gastropod Rapana venosa. Scientific Reports, 6(1), e86508. https://doi.org/10.1038/srep23461

Yusa, Y. (1996). The effects of body size on mating features in a field population of the hermaphroditic sea hare Aplysia kurodai Baba, 1937 (Gastropoda: Opisthobranchia). Journal of Molluscan Studies, 62(3), 381-386. https://doi.org/10.1093/mollus/62.3.381

Zahradnik, T. D., Lemay, M. A., \& Boulding, E. G. (2008). Choosy males in a littorinid gastropod: Male Littorina subrotundata prefer large and virgin females. Journal of Molluscan Studies, 74(3), 245-251. https://doi.org/10.1093/mollus/eyn014 


\section{Figure and Table legends}

720 Figure 1. Explanation of the selection consequences of the same mating preference

721 mechanism in males (males of size $S$ prefer to mate with females of size $S+X, X$ being

722 any specific positive value) on differential a priori sexual size dimorphism scenarios

723 (scenarios A and B). The black normal distributions represent the male size distribution

724 in a hypothetical population, and two alternative female size distributions (scenarios

$725 \mathrm{~A}$ and $\mathrm{B}$ ). The red normal curves represent the hypothetical mating preference of

726 males in the population (notice that the preference distribution is displaced from the

727 male size distribution by a factor $X$ ). Scenario $A$ assumes a low sexual size dimorphism,

728 and therefore the average male will choose (with the same mating preference; red

729 curve) the largest (within female size distribution) females, therefore causing a

730 positive SSf. Under scenario B, due to a large sexual size dimorphism, the same males

731 will choose females which are the smallest females within the female size distribution,

732 therefore causing negative SSf. Notice that in the two scenarios, the male mate choice

733 distribution has not changed (red distribution) but the resulting chosen female size

734 distribution changes depending on the particular level of size dimorphism in the 735 population. 
737 Figure 2. Frequency of male trail following (as percentage of cases observed; Figure

738 2a) and copulation duration between the two mating categories (white bars: females

739 smaller than males; black bar: females larger than males; Figure $2 b$ ) in the three

740 littorinids, Echinolittorina malaccana, E. radiata and E. vidua, at Cape d' Aguilar Marine

741 Reserve, Hong Kong. Significantly different results are indicated by asterisks $(* P<0.05$,

$742 \quad * * P<0.01, * * * P<0.001)$.

743

744 Figure 3. Relationship between $\mathrm{SS}_{\mathrm{f}}$ and sexual size dimorphism (both standardized) for

745 the whole data set (light squares) and for the means within the seven species (dark

746 circles). Correlation values and statistical significances are given in the text.

747

748

749 
SCENARIO A

SCENARIO B

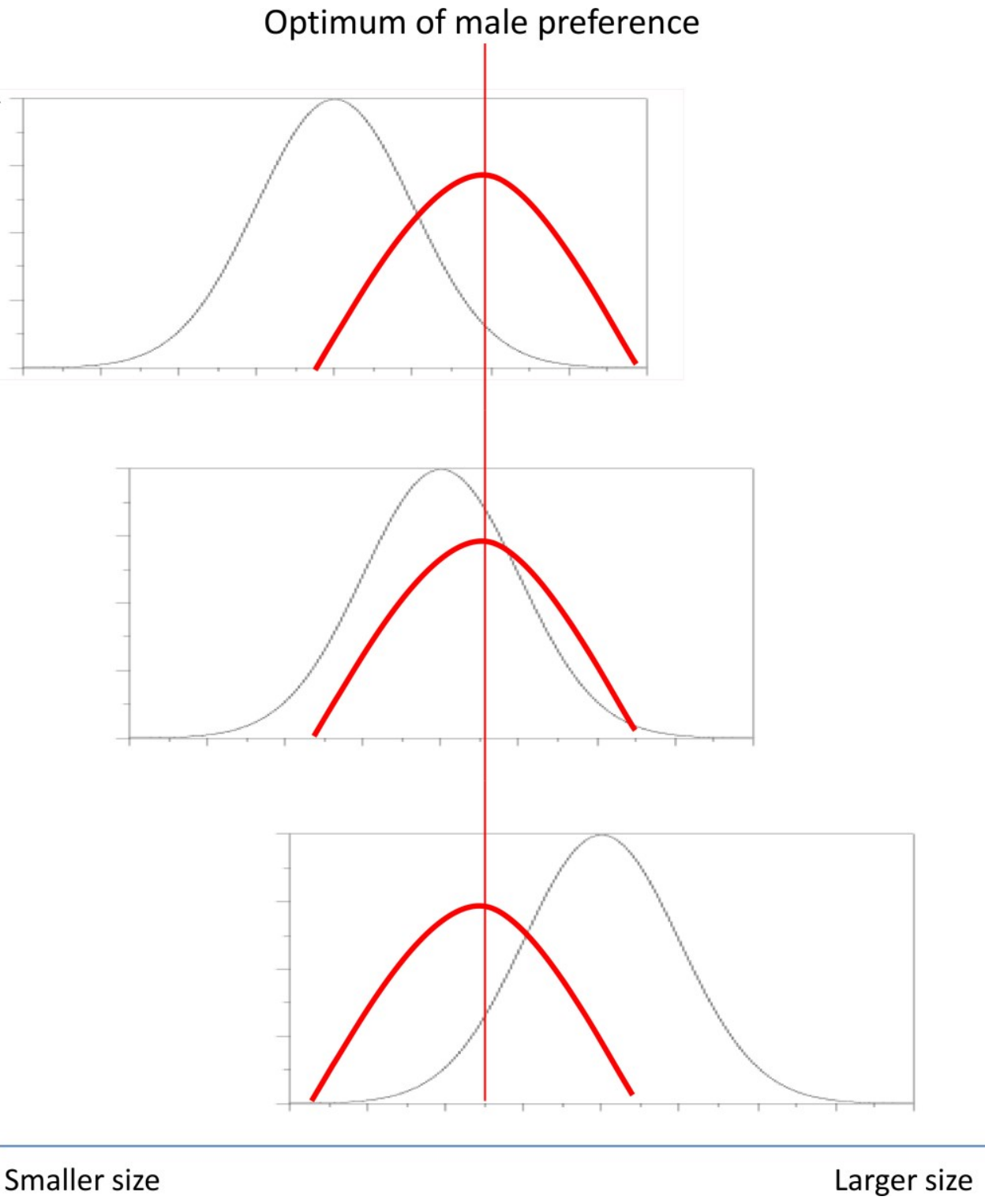

FEMALE SIZE

DISTRIBUTION

FEMALE SIZE DISTRIBUTION 


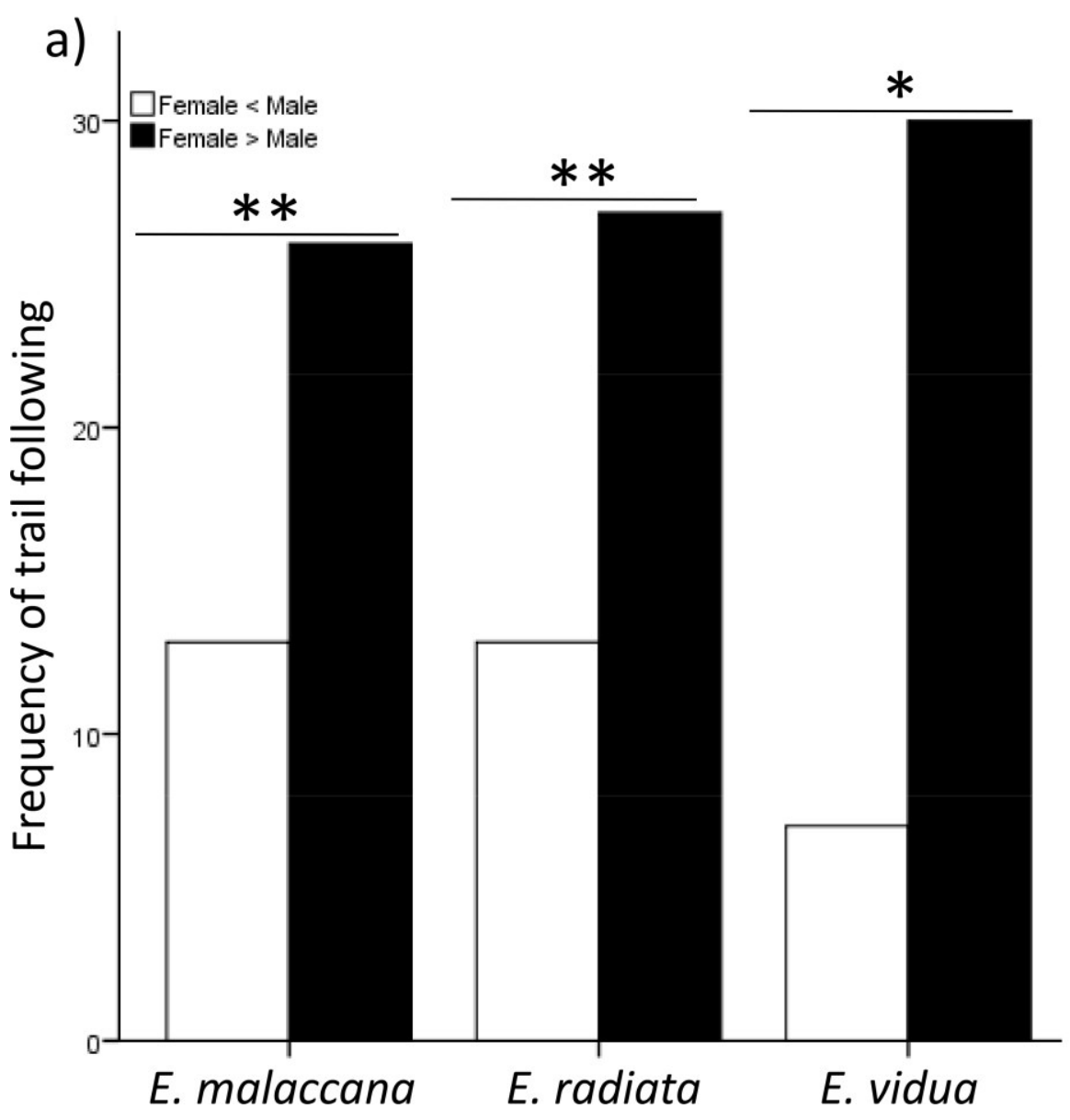

Figure 1

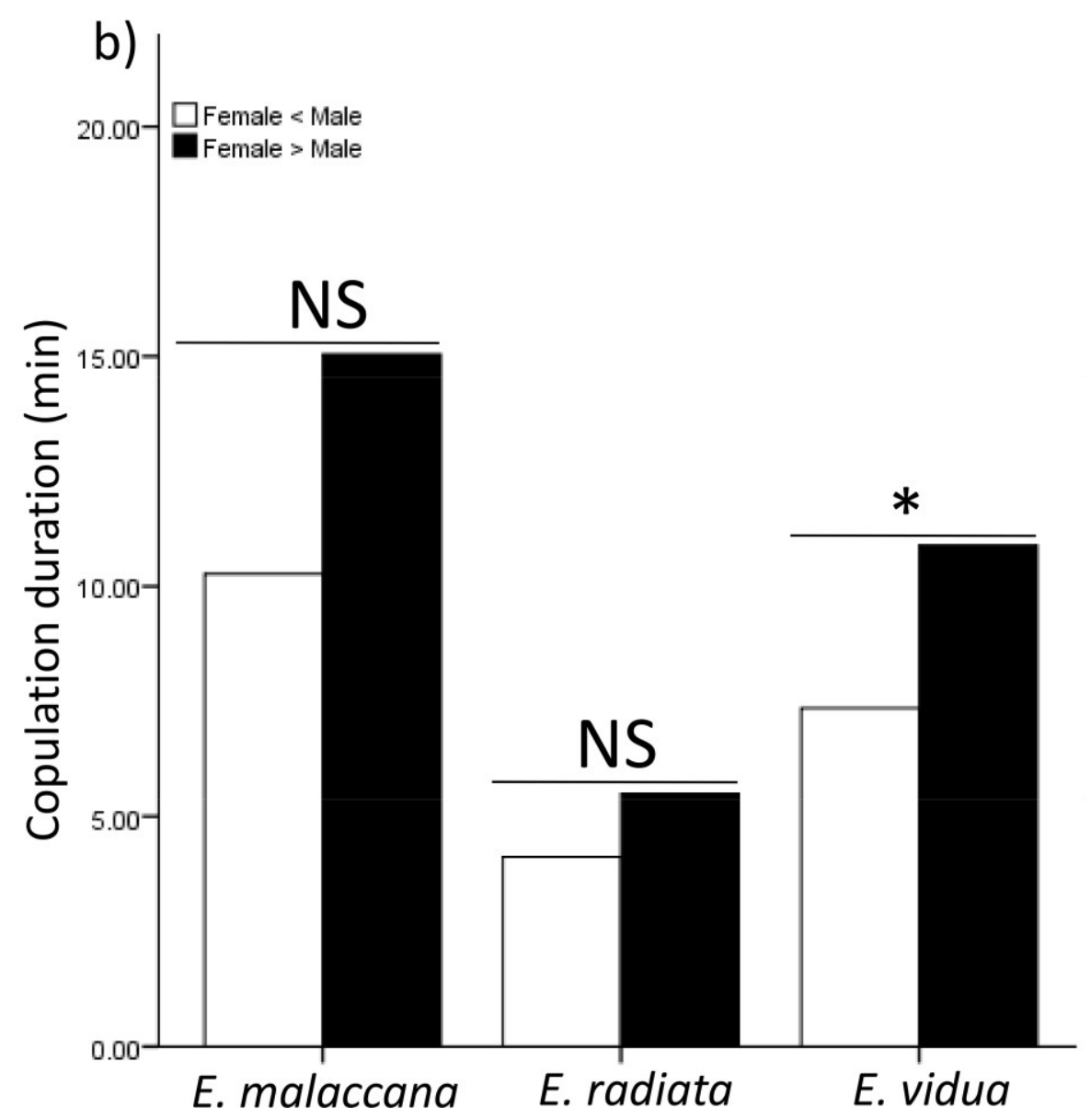

Figure 2 


\begin{tabular}{|c|c|c|c|c|c|c|}
\hline Species & $\begin{array}{l}\text { Reproductive } \\
\text { mode }\end{array}$ & $\begin{array}{l}\text { Developmental } \\
\text { mode }\end{array}$ & $\begin{array}{l}\text { Sex } \\
\text { Ratio ir }\end{array}$ & $\begin{array}{l}\text { Sexual } \\
\text { Dimorphism } \\
\text { n size }\end{array}$ & $\begin{array}{l}\text { Mating } \\
\text { pattern } \\
\text { (size) }\end{array}$ & Reference \\
\hline Siphonaria capensis & $\mathrm{H}$ & $\mathrm{P}$ & - & - & $S R=S D$ & (Pal, Erlandsson, \& Sköld, 2006) \\
\hline Aplysia vaccaria & $\mathrm{H}$ & $\mathrm{P}$ & - & - & $S R>S D$ & (Angeloni \& Bradbury, 1999) \\
\hline Aplysia punctata & $\mathrm{H}$ & $\mathrm{P}$ & - & - & $\mathrm{SR}>\mathrm{SD}$ & (Otsuka, Yves, \& Tobach, 1980) \\
\hline Aplysia kurodai & $\mathrm{H}$ & $P$ & - & - & $\mathrm{SR}>\mathrm{SD}$ & (Yusa, 1996) \\
\hline Alderia modesta & $\mathrm{H}$ & $P$ & - & - & $\mathrm{SR}>\mathrm{SD}$ & (Angeloni, 2003) \\
\hline Buccinanops globulosus & $\mathrm{Di}$ & D & $q$ bias $\uparrow$ & $+>0^{x}$ & o > $0^{x}$ & (Avaca, Narvarte, \& Martín, 2012, 2013) \\
\hline Littoraria flava & $\mathrm{Di}$ & $\mathrm{P}$ & 우 bias & 우>송 & 우>송 & (Cardoso et al., 2007) \\
\hline Angustassiminea castanea & $\mathrm{Di}$ & $P$ & & 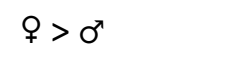 & $q>\sigma^{\pi}$ & (Kurata \& Kikuchi, 2000) \\
\hline Assiminea japonica & $\mathrm{Di}$ & $P$ & & $\sigma^{\prime}>q$ & $0^{x}>9$ & (Kurata \& Kikuchi, 2000) \\
\hline Littoraria ardouiniana & $\mathrm{Di}$ & $\mathrm{P}$ & $\sigma^{x}$ bias & 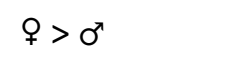 & o > $\sigma^{x}$ & (Ng et al., 2013; Ng \& Williams, 2014) \\
\hline Littoraria melanostoma & $\mathrm{Di}$ & $P$ & $1: 1$ & 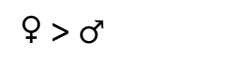 & $q>\sigma^{\pi}$ & (Ng, 2013) \\
\hline Echinolittorina malaccana & $\mathrm{Di}$ & $P$ & $1: 1$ & \& > $0^{x}$ & o > $0^{\pi}$ & This study \\
\hline Echinolittorina radiata & $\mathrm{Di}$ & $P$ & $q$ bias & 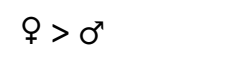 & $q>\sigma^{x}$ & This study \\
\hline Echinolittorina radiata & $\mathrm{Di}$ & $\mathrm{P}$ & $\sigma^{\pi}$ bias & 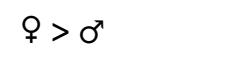 & \& > $\sigma^{x}$ & (Ito \& Wada, 2006) \\
\hline Echinolittorina vidua & $\mathrm{Di}$ & $\mathrm{P}$ & bias & $\varphi=0^{n}$ & $q>\sigma^{\pi}$ & This study \\
\hline Littorina saxatilis $s_{c r a b}$ & $\mathrm{Di}$ & $\mathrm{D}$ & $1: 1$ & P > $0^{x}$ & Q > $0^{x}$ & $\begin{array}{l}\text { (Erlandsson \& Rolán-Alvarez, 1998; Hollander et al., } \\
\text { 2005; Hull, 1998; Johannesson et al., 1995; RolánAlvarez } \\
\text { et al., 1999; Saur, 1990) this study }\end{array}$ \\
\hline Littorina saxatilis $_{\text {wave }}$ & $\mathrm{Di}$ & D & $1: 1$ & 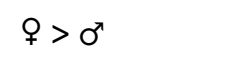 & o > $\sigma^{x}$ & This study \\
\hline Littorina fabalis & $\mathrm{Di}$ & D & $1: 1$ & P > $0^{x}$ & Q > $0^{\pi}$ & This study \\
\hline Littorina littorea & $\mathrm{Di}$ & $\mathrm{P}$ & $1: 1$ & 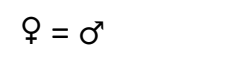 & Q $>\sigma^{x}$ & (Erlandsson \& Johannesson, 1994; Saur, 1990) \\
\hline
\end{tabular}

A review of reproductive traits and mating patterns in relation to individual size in marine gastropods. Remark: The above studies were identified by searching in ISI

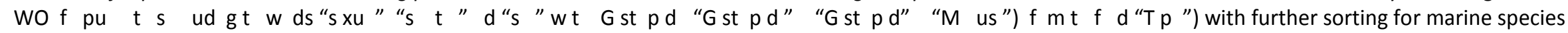
in November 2017. Abbreviations: $\mathrm{H}=$ hermaphrodite, $\mathrm{Di}=$ dioecious, $\mathrm{D}=$ direct, $\mathrm{P}=$ planktonic, $\mathrm{SR}=$ sperm recipient and $\mathrm{SD}=$ sperm donor. 
780 Table 2. Analysis of sexual selection on size (shell length).

\begin{tabular}{|c|c|c|c|c|c|c|c|c|c|c|}
\hline \multirow[b]{3}{*}{ Species } & \multirow[b]{3}{*}{ Locality } & \multirow[b]{3}{*}{ Reference } & \multirow[b]{3}{*}{$\mathrm{Nm}$} & \multirow[b]{3}{*}{$\mathrm{Nu}$} & \multicolumn{3}{|c|}{ ALE SIZE (mm) } & \multicolumn{3}{|c|}{ FEMALE SIZE (mm) } \\
\hline & & & & & \multirow{2}{*}{$\begin{array}{c}\text { Mated } \\
\text { (Mean } \pm \\
\text { SD) }\end{array}$} & \multicolumn{2}{|l|}{ Unmated } & \multirow{2}{*}{$\begin{array}{c}\text { Mated } \\
\text { (Mean } \pm \\
\text { SD) }\end{array}$} & \multirow{2}{*}{$\begin{array}{c}\text { Unmated } \\
\text { (Mean } \pm \\
\text { SD) }\end{array}$} & \multirow[b]{2}{*}{$\mathrm{SS}_{\mathrm{f}}$} \\
\hline & & & & & & $\begin{array}{l}\text { (Mean } \pm \\
\text { SD) }\end{array}$ & $\mathrm{SS}_{\mathrm{m}}$ & & & \\
\hline \multirow{4}{*}{ E. malaccana } & ShekO 2015 & Ng et al., 2016 & 80 & 155 & $6.04 \pm 1.01$ & $5.71 \pm 1.30$ & 0.19 & $6.49 \pm 1.23$ & $5.56 \pm 1.47$ & $0.40^{* * *}$ \\
\hline & Cp d' Agu 2012 & This study & 102 & 266 & $8.65 \pm 0.88$ & $8.18 \pm 0.99$ & $0.34^{* *}$ & $9.01 \pm 0.98$ & $8.46 \pm 1.14$ & $0.36^{* *}$ \\
\hline & Cp d' Agu 2015 & Ng et al., 2016 & 456 & 905 & $8.44 \pm 1.38$ & $8.11 \pm 1.44$ & $0.15^{* *}$ & $9.23 \pm 1.45$ & $8.53 \pm 1.58$ & $0.30^{* * *}$ \\
\hline & Mean \pm SD & \multirow{4}{*}{$\begin{array}{l}\text { This study Ng } \\
\text { et al., } 2016\end{array}$} & & & \multicolumn{3}{|r|}{$0.23 \pm 0.185$} & \multicolumn{3}{|r|}{$\begin{array}{c}0.35^{* *} \pm \\
0.253\end{array}$} \\
\hline \multirow{3}{*}{ E. radiata } & Cp d' Agu 2012 & & 108 & 247 & $6.36 \pm 1.51$ & $6.12 \pm 1.68$ & 0.09 & $7.73 \pm 1.62$ & $7.47 \pm 1.86$ & 0.11 \\
\hline & \multirow{2}{*}{ Mean \pm SD } & & 102 & 198 & $7.27 \pm 1.54$ & $6.83 \pm 1.62$ & 0.16 & $8.22 \pm 1.53$ & $7.53 \pm 1.80$ & $0.27^{*}$ \\
\hline & & & & & \multicolumn{3}{|r|}{$0.12 \pm 0.049$} & \multicolumn{3}{|r|}{$0.19 \pm 0.113$} \\
\hline E. vidua & Cp d' Agu 2012 & This study & 82 & 126 & $6.97 \pm 1.06$ & $6.72 \pm 1.14$ & 0.13 & $7.41 \pm 1.02$ & $6.73 \pm 1.36$ & $0.33^{* *}$ \\
\hline \multirow[t]{2}{*}{ Littoraria flava } & \multirow[t]{2}{*}{ Flexeira 2001} & $\begin{array}{c}\text { Cardoso et al., } \\
2007\end{array}$ & 480 & 243 & $10.8 \pm 1.72$ & $10.9 \pm 2.28$ & -0.06 & $11.8 \pm 1.80$ & $10.9 \pm 2.31$ & $0.37^{* * *}$ \\
\hline & & This study & 190 & 375 & $6.98 \pm 0.67$ & $6.68 \pm 0.95$ & $0.22^{* * *}$ & $7.60 \pm 0.78$ & $6.96 \pm 1.13$ & $0.25^{* * *}$ \\
\hline \multirow[b]{2}{*}{ Littorina fabalis } & Abelleira 2014 & This study & 292 & 549 & $6.63 \pm 0.81$ & $6.34 \pm 0.89$ & $0.22^{* *}$ & $7.42 \pm 0.97$ & $7.05 \pm 0.96$ & $0.24^{* * *}$ \\
\hline & $\begin{array}{l}\text { Abelleira } 2016 \\
\text { Mean } \pm \text { SD }\end{array}$ & & & & & & $0.22^{* *} \pm$ & & & \multirow[t]{2}{*}{$0.24^{* *} \pm 0.01$} \\
\hline \multirow{5}{*}{ L. littorea } & & & & & & & 0.00 & & & \\
\hline & Långholmen 2014 & This study & 88 & 333 & $19.5 \pm 2.05$ & $19.1 \pm 2.50$ & 0.17 & $19.2 \pm 2.87$ & $18.0 \pm 3.45$ & $0.36^{*}$ \\
\hline & Saltö W'1994 & E \& R-A, 1998 & 44 & 74 & $11.5 \pm 1.21$ & $10.4 \pm 2.17$ & $0.34^{*}$ & $12.0 \pm 1.17$ & $11.1 \pm 2.31$ & 0.29 \\
\hline & Saltö S1994 & E \& R-A, 1998 & 46 & 53 & $11.2 \pm 1.39$ & $10.4 \pm 2.17$ & $0.45^{* *}$ & $12.1 \pm 1.77$ & $10.9 \pm 1.75$ & $0.35^{*}$ \\
\hline & Ängklavenbukten $_{199}$ & E \& R-A, 1998 & 44 & 83 & $10.1 \pm 1.04$ & $8.8 \pm 1.58$ & $0.57^{* * *}$ & $10.7 \pm 1.01$ & $9.6 \pm 1.65$ & $0.45^{* *}$ \\
\hline
\end{tabular}




\begin{tabular}{|c|c|c|c|c|c|c|c|c|c|c|}
\hline & Långholmen 2014 & This study & 96 & 365 & $10.6 \pm 1.31$ & $10.3 \pm 1.47$ & 0.21 & $10.8 \pm 1.54$ & $9.4 \pm 2.34$ & $0.61^{* * *}$ \\
\hline & $M P a n+C R$ & & & & & & $0.39^{*} \pm$ & & & $0^{* *}+0140$ \\
\hline \multirow{4}{*}{ L. saxatiliswave } & & & & & & & 0.154 & & & \\
\hline & Saltö11994 & E \& R-A, 1998 & 76 & 167 & $5.5 \pm 1.44$ & $6.0 \pm 1.65$ & -0.20 & $6.2 \pm 1.06$ & $7.1 \pm 1.76$ & $-0.38^{*}$ \\
\hline & Saltö2 1994 & E \& R-A, 1998 & 76 & 167 & $4.7 \pm 0.91$ & $5.1 \pm 0.77$ & -0.33 & $5.6 \pm 1.05$ & $5.7 \pm 1.19$ & -0.06 \\
\hline & Mean \pm SD & & & & & & $-0.27 \pm$ & & & $-0.22 \pm 0.226$ \\
\hline
\end{tabular}


Analysis of sexual selection on size (shell length) in males and females of seven littorinid species from three genera with locality and year of study. $\mathrm{Nm}=$ sample size of mated individuals and $\mathrm{Nu}=$ sample size of unmated (reference) individuals. Sexual selection intensity (SSm and SSf) index is the difference between mated and unmated males or females standardized by the SD of shell length of the population of males or females (see Erlandsson \& Rolán-Alvarez, 1998). E \& R-A 1998 is Erlandsson \& RolánAlvarez, 1998. 
Table 3. Evaluation of the mate choice mechanism

787

\begin{tabular}{|c|c|c|c|c|c|c|c|}
\hline Species & $\begin{array}{l}\text { Expected malemale } \\
\text { trail following }\end{array}$ & $\begin{array}{l}\text { Expected } \\
\text { malefemale trail } \\
\text { following }\end{array}$ & $\begin{array}{l}\text { Observed } \\
\text { malemale trail } \\
\text { following }\end{array}$ & $\begin{array}{l}\text { Observed } \\
\text { malefemale } \\
\text { trail following }\end{array}$ & $x^{2}$ & $P$ & $n$ \\
\hline E. malaccana & 23 (48.1\%) & 24 (51.9\%) & 5 (10.6\%) & 42 (89.4\%) & 27.587 & $<0.001$ & 47 \\
\hline E. radiata & 21 (41.2\%) & 29 (58.8\%) & 6 (12.0\%) & 44 (88.0\%) & 18.473 & $<0.001$ & 50 \\
\hline E. vidua & 17 (40.5\%) & 26 (59.5\%) & 3 (7.0\%) & 40 (93.0\%) & 19.068 & $<0.001$ & 43 \\
\hline
\end{tabular}

788 Chi-square tests to examine whether males followed females more than males than would be predicted by chance (taking into account the size distribution of females 789 in the sample). Expected (derived from sex ratios) and observed frequencies of males mounting conspecific males and females in the three littorinids: Echinolittorina 790 malaccana, E. radiata and E. vidua.

791

792 


\section{Regression of size on copulation duration}

793 Table 4. Male and female size contribution to copulation duration

\begin{tabular}{|c|c|c|c|c|c|c|c|c|}
\hline \multirow[b]{2}{*}{ Species } & \multirow[b]{2}{*}{$\begin{array}{c}\text { Copulation } \\
\text { Duntition }\end{array}$} & & \multicolumn{3}{|c|}{ Full Model } & \multicolumn{3}{|c|}{ Step-Wise } \\
\hline & & $\mathrm{N}$ & Explained & $\begin{array}{l}\text { Variables } \\
\text { in Model }\end{array}$ & $\begin{array}{c}\text { Partial } \\
r\end{array}$ & Explained & Variable Chosen & Partial $r$ \\
\hline \multirow[t]{2}{*}{ E. malaccana } & $13.8 \pm 9.46$ & 41 & $27.10 \%$ & Male & -0.02 & $27.10 \%$ & Female & $0.52^{* * *}$ \\
\hline & & & & Female & $0.49^{* * *}$ & & & \\
\hline \multirow[t]{2}{*}{ E. radiata } & $5.0 \pm 2.87$ & 42 & $13.80 \%$ & Male & $-0.31^{*}$ & n.s. & Male/Female & n.s. \\
\hline & & & & Female & $0.32^{*}$ & & & \\
\hline \multirow[t]{2}{*}{ E. vidua } & $10.3 \pm 3.91$ & 38 & $11.60 \%$ & Male & -0.09 & & & \\
\hline & & & & Female & $0.29^{m}$ & $10.90 \%$ & Female & $0.33^{*}$ \\
\hline
\end{tabular}

794 Multiple regressions to evaluate the contribution of male and female size to the variation in copulation duration in three Echinolittorina species. Both the full model 795 approach and the step-wise regressions gave similar results in relating male and female size to copulation duration in two of the three species, with the exception of 796 Echinolittorina radiata. In E. malaccana female size was clearly the best predictor of copulation time, but this was less clear in E. vidua; while in E. radiata similar 797 contributions of both male and female size (but in different directions) determined copulation duration. Copulation duration was generally longer in $E$. malaccana than 798 in E. vidua, and longer in E. vidua than in E. radiata. Significant results are indicated by asterisks (n.s. $=$ not significant, ${ }^{m} p=0.082, * p<0.05,{ }^{* *} p<0.01, * * * p$ $<0.001)$. 
801

802

803

804

805

806 